\title{
Nordic Seas dissolved oxygen data in CARINA
}

\author{
E. Falck ${ }^{1,2}$ and A. Olsen ${ }^{2}$ \\ ${ }^{1}$ Geophysical Institute, University of Bergen, Allégaten 70, 5007 Bergen, Norway \\ ${ }^{2}$ Bjerknes Centre for Climate Research, Uni Research, Allégaten 55, 5007 Bergen, Norway \\ Received: 17 September 2009 - Published in Earth Syst. Sci. Data Discuss.: 22 October 2009 \\ Revised: 3 March 2010 - Accepted: 16 March 2010 - Published: 12 April 2010
}

\begin{abstract}
Water column data of carbon and carbon relevant hydrographic and hydrochemical parameters from 188 previously non-publicly available cruises in the Arctic, Atlantic, and Southern Oceans have been retrieved and merged into a new database: CARINA (CARbon IN the Atlantic). This paper is one of a series of papers related to the CARINA project and presents an account of the quality control of the oxygen data from the Nordic Seas (the Greenland, Norwegian, and Iceland Seas) in CARINA. Out of 35 cruises from the Nordic Seas included in CARINA, 32 had oxygen data, spanning the period from 1982 to 2006 . These data have been subject to rigorous quality control in order to ensure highest possible quality and consistency. Oxygen data from four cruises have been adjusted in the final CARINA data product.
\end{abstract}

\section{Data coverage and parameter measured}

Repository-Reference: doi:10.3334/CDIAC/otg.CARINA.AMS.V1.2

Available at: http://cdiac.ornl.gov/ftp/oceans/CARINA/CARINA_Database/CARINA.AMS.V1.2/

Coverage: $59.60^{\circ} \mathrm{N}-82.35^{\circ} \mathrm{N}, 35.23^{\circ} \mathrm{W}-20.01^{\circ} \mathrm{E}$

Location Name: Nordic Seas

Date/Time Start: 1982-02-28

Date/Time End: 2006-02-10

\begin{tabular}{lllll}
\hline $\begin{array}{l}\text { Data Product } \\
\text { Parameter Name }\end{array}$ & $\begin{array}{l}\text { Data Product } \\
\text { Flag name }\end{array}$ & $\begin{array}{l}\text { Exchange File } \\
\text { Parameter Name }\end{array}$ & $\begin{array}{l}\text { Exchange File } \\
\text { Flag Name }\end{array}$ & Unit \\
\hline $\begin{array}{l}\text { station } \\
\text { day } \\
\text { month }\end{array}$ & $\begin{array}{l}\text { STANBR } \\
\text { DATE }\end{array}$ & & \\
year & DATE & & \\
$\begin{array}{l}\text { latitude } \\
\text { longitude } \\
\text { cruiseno }\end{array}$ & & DATE & & decimal degree \\
depth & & LATITUDE & & decimal degree \\
temperature & & LONGITUDE & & meter \\
salinity & & & & ${ }^{\circ} \mathrm{C}$ \\
$\begin{array}{l}\text { ctdsal } \\
\text { pressure } \\
\text { oxygen }\end{array}$ & sf & CTDTMP & & \\
\hline
\end{tabular}

For a complete list of all parameters available in CARINA see Key et al. (2010).

Note the different names for the parameters in the Exchange files (the individual cruise files) and the merged data product.

Correspondence to: E. Falck

(eva.falck@gfi.uib.no) 


\section{Introduction}

CARINA (CARbon IN the Atlantic) is a database of carbon and carbon-relevant data from hydrographic cruises in the Arctic, Atlantic, and Southern Oceans. The project started as an essentially informal, unfunded project in Delmenhorst, Germany, in 1999 during the workshop on " $\mathrm{CO}_{2}$ in the North Atlantic", with the main goal to create a uniformly formatted database of carbon relevant variables in the ocean to be used for accurate assessments of oceanic carbon inventories and uptake rates (Key et al., 2010; Tanhua et al., 2010a). The collection of data and the quality control (QC) of the data have been the main focus of the CARINA project.

This paper provides an overview of the oxygen data from the Nordic Seas data in CARINA and describes the QC of these data. During the primary QC the data were objectively studied in order to identify outliers and errors while the secondary QC aimed at quantifying systematic differences in the reported values due to analytical errors. Crossover analyses were applied during the secondary QC and the offsets derived were used to calculate corrections of the oxygen measured on individual cruises using least square models (Tanhua et al., 2010a).

The Nordic Seas oxygen data are part of the Arctic Mediterranean Seas subset of CARINA (CARINA-AMS). This subset includes data from both the Nordic Seas and the Arctic Ocean. Other Nordic Seas data that have been subject to QC are described in Olsen et al. (2009, salinity), Olafsson and Olsen (2010, nutrients), Olsen (2009a, total inorganic carbon, and 2009b, total alkalinity), and Jeansson et al. (2010, CFCs). All data from the Arctic Ocean are described in Jütterström et al. (2010).

The CARINA database consists of two parts: the first part is the set of the individual cruise files where all the data reported by the measurement teams are stored. Quality flags are accompanying the data, and the files are in WHP (WOCE Hydrographic Program) exchange format where the first lines are the condensed metadata. There are essentially no calculated or interpolated values in the individual cruise files, with the exceptions of pressure calculated from depth and some bottle salinities that were replaced by the salinity measured with the CTD instrument.

The second part of CARINA consists of three merged, quality controlled, and adjusted data files; one each for the Atlantic Ocean, Arctic Mediterranean Seas, and Southern Ocean regions. These files contain all the CARINA data and also include: 1) interpolated values for nutrients, oxygen, and salinity if those data were missing and the interpolation could be made according to certain criteria as described in Key et al. (2010); 2) calculated carbon parameters (e.g. if total inorganic carbon and alkalinity were measured, $\mathrm{pH}$ was calculated); and 3) instances where bottle salinities, when missing or bad, were replaced by CTD salinity. Calculated or interpolated values have been given the quality flag " 0 ". A more comprehensive description of the complete CARINA

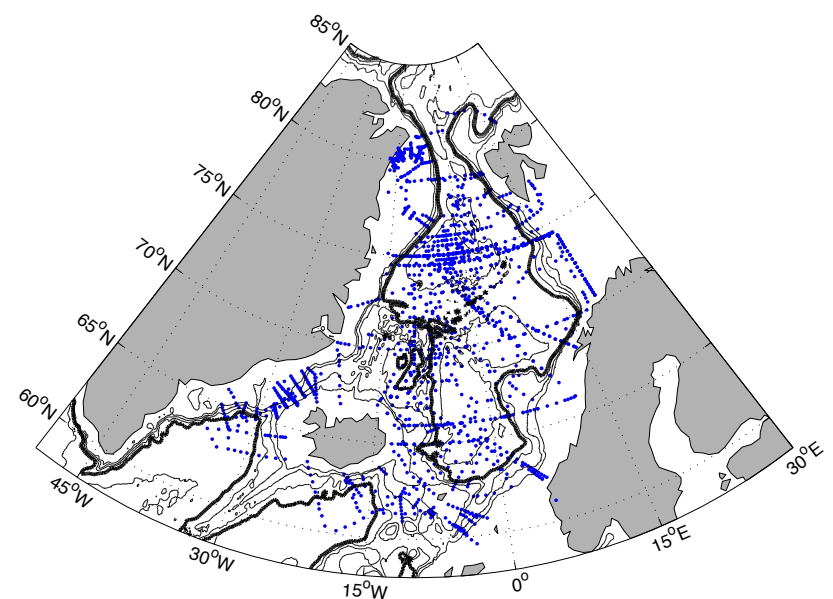

Figure 1. The Nordic Seas with oxygen sampling positions. Bathymetry has been drawn at 500, 1000, 1500, 1900, 3000 and $4000 \mathrm{~m}$, with the $1900 \mathrm{~m}$ isobath in bold.

database can be found in Key et al. (2010), as well as in the other, more specialised, papers in this special issue, which includes the paper describing the oxygen data from the Atlantic Ocean region of CARINA (Stendardo et al., 2009).

\section{Oxygen data}

Out of the 188 CARINA cruises, 62 are included in CARINA-AMS, and 35 of these are considered as Nordic Seas cruises. The Nordic Seas is defined as the region closed by the Fram Strait to the north, Greenland to the west, the Greenland-Scotland Ridge to the south, and Norway, the Barents Sea Opening, and Spitsbergen to the east. Five of the Nordic Seas cruises are in common with the Atlantic Ocean subset of CARINA (Tanhua et al., 2010b), which ensures consistency between the regions. Of the 35 cruises included in the Nordic Seas, 32 had oxygen data and these cruises are listed in Table 1. Each cruise is uniquely identified by a CARINA cruise number (between 1 and 188) and an expocode which consists of two characters identifying the country code followed by the two character vessel NODC (National Oceanographic Data Center) code and the last eight numbers denoting the starting date of the cruise (as YYYYMMDD). A list of ships included in the CARINA Nordic Seas data can be found in Olsen et al. (2009).

All station positions for the Nordic Seas oxygen data are shown in Fig. 1 while Fig. 2 shows the same for each cruise. The cruises in Fig. 2 are shown in the same order as in Table 1, i.e. sorted by CARINA cruise number and not by year. The earliest cruise is the 1982 CSS Hudson (18HU19820228 (36)) and the latest the 2003 G. O. Sars cruise (58GS20030922 (128)). The parenthesis show the expocode of the cruise while the number in brackets inserted after the expocode denotes the CARINA cruise number. 

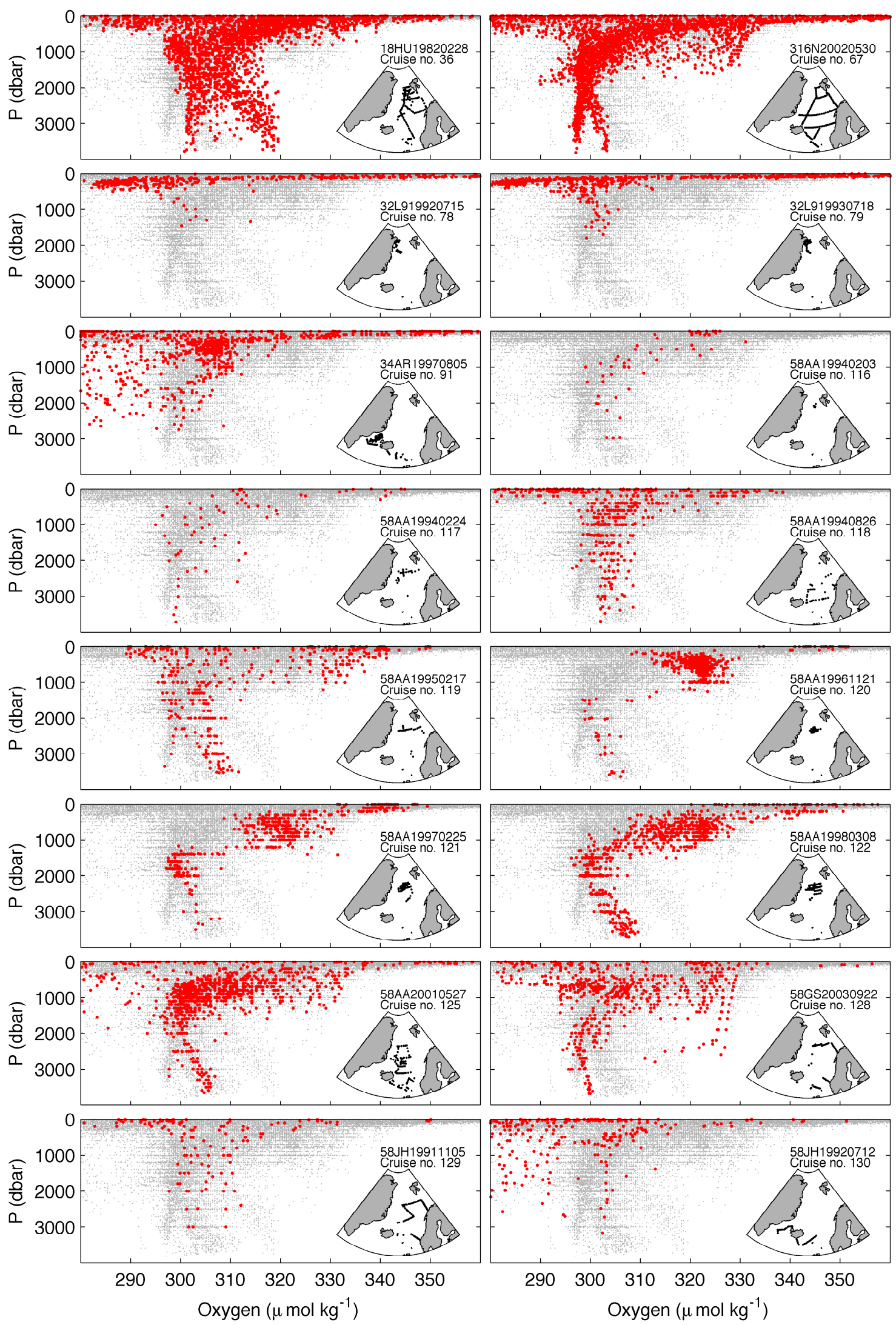

Figure 2. Station positions and oxygen data of Nordic Seas CARINA cruises after secondary QC. All data shown in grey and specific cruise in red. 

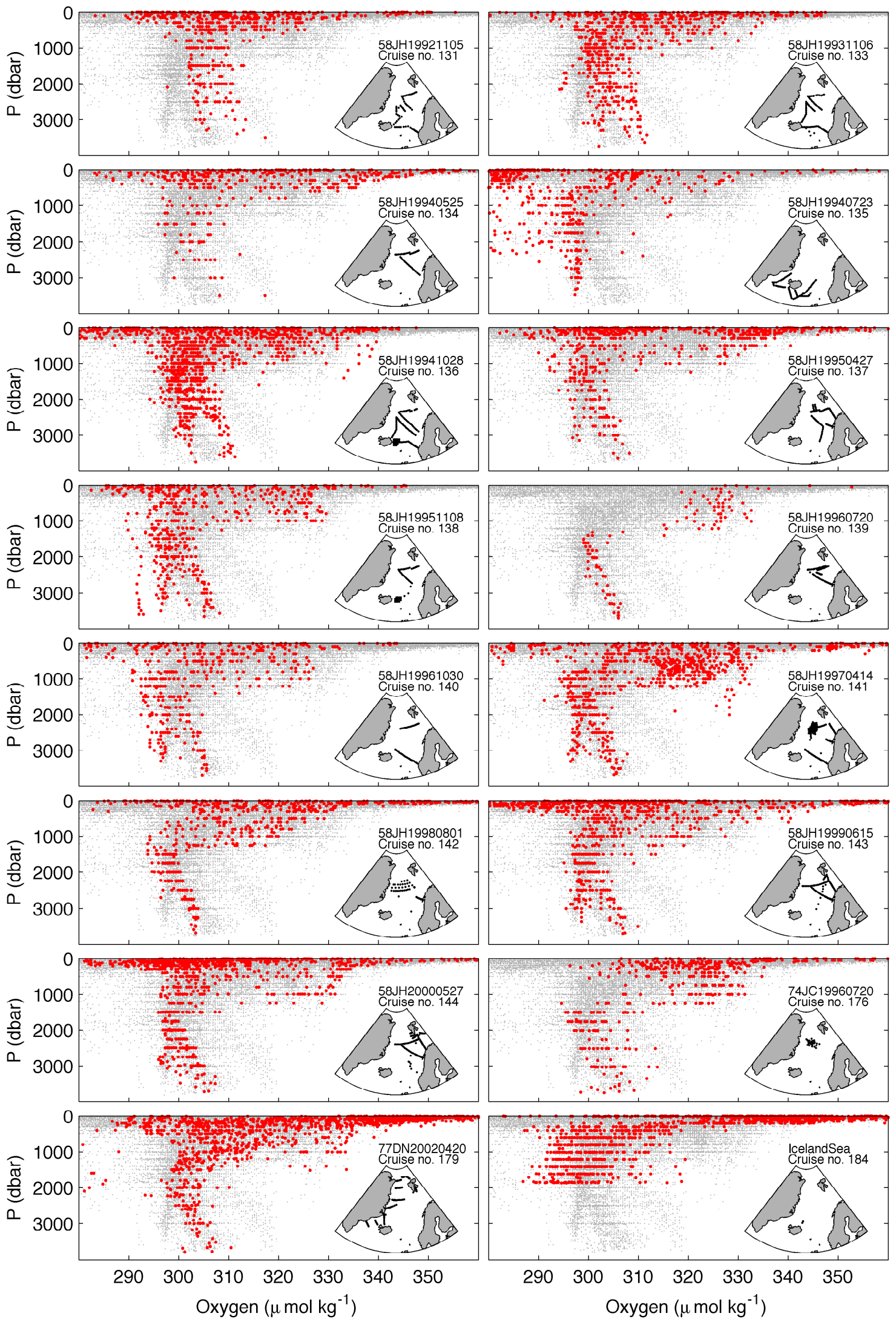

Figure 2. Continued. 
Table 1. CARINA cruises with dissolved oxygen data in the Nordic Seas.

\begin{tabular}{|c|c|c|c|c|}
\hline No. $^{\mathrm{a}}$ & EXPOCODE & Country/Institute & PI & Rec. $^{b}$ \\
\hline 36 & 18HU19820228 & Canada/BIO & P. Jones & 1 \\
\hline 67 & $316 \mathrm{~N} 20020530$ & USA/Scripps & J. Swift & 1 \\
\hline 78 & 32L919920715 & USA/Brookhaven & D. Wallace & $\mathrm{NC}$ \\
\hline 79 & 32L919930718 & USA/Brookhaven & D. Wallace & $\mathrm{NC}$ \\
\hline 91 & 34AR19970805 & Sweden/UGOT & T. Tanhua & $\mathrm{NC}$ \\
\hline 116 & 58AA19940203 & Norway/UoB & T. Johannessen & 1 \\
\hline 117 & 58AA19940224 & Norway/UoB & T. Johannessen & 1 \\
\hline 118 & 58AA19940826 & Norway/UoB & T. Johannessen & 1 \\
\hline 119 & 58AA19950217 & Norway/UoB & T. Johannessen & 1 \\
\hline 120 & 58AA19961121 & Norway/UoB & E. Falck & 0.98 \\
\hline 121 & 58AA19970225 & Norway/UoB & E. Falck & 0.99 \\
\hline 122 & 58AA19980308 & Norway/UoB & T. Johannessen & 0.99 \\
\hline 125 & 58AA20010527 & Norway/UoB & T. Johannessen & 1 \\
\hline 128 & $58 G S 20030922$ & Norway/UoB & T. Johannessen & 1 \\
\hline 129 & 58JH19911105 & Norway/IMR & F. Rey & 1 \\
\hline 130 & 58JH19920712 & Norway/IMR & F. Rey & $\mathrm{NC}$ \\
\hline 131 & 58JH19921105 & Norway/IMR & F. Rey & 1 \\
\hline 133 & 58JH19931106 & Norway/IMR & F. Rey & 1 \\
\hline 134 & 58JH19940525 & Norway/IMR & F. Rey & 1 \\
\hline 135 & 58JH19940723 & Norway/IMR & F. Rey & $\mathrm{NC}$ \\
\hline 136 & 58JH19941028 & Norway/IMR & F. Rey & 1 \\
\hline 137 & 58JH19950427 & Norway/IMR & F. Rey & 1 \\
\hline 138 & 58JH19951108 & Norway/IMR & F. Rey & 1 \\
\hline 139 & 58JH19960720 & Norway/IMR & F. Rey & 1 \\
\hline 140 & 58JH19961030 & Norway/IMR & F. Rey & 1 \\
\hline 141 & 58JH19970414 & Norway/IMR & F. Rey & 1 \\
\hline 142 & 58JH19980801 & Norway/IMR & F. Rey & 1 \\
\hline 143 & 58JH19990615 & Norway/IMR & F. Rey & 1 \\
\hline 144 & $58 \mathrm{JH} 20000527$ & Norway/IMR & F. Rey & 1 \\
\hline 176 & 74JC19960720 & England/UEA & A. Watson & 0.98 \\
\hline 179 & 77DN20020420 & Sweden/UGOT & E. Falck & 1 \\
\hline 184 & Iceland Sea time series & Iceland/MRI & J. Olafsson & $\mathrm{NC}$ \\
\hline
\end{tabular}

${ }^{a}$ CARINA cruise number, is cruise identifier in merged file.

${ }^{\mathrm{b}}$ Recommendations from the secondary QC. Numbers are the multiplicative adjustments.

$\mathrm{NC}=$ not considered (see Sects. 3.2 and 3.3.2 for explanation).

Oxygen was measured with Winkler titration except for 58AA19980308, 58AA20010527, 58GS20030922.

The most recent data are part of the Iceland Sea time series (184), which includes data from August 1991 through February 2006. Except for the CSS Hudson cruise in 1982 (18HU19820228 (36)), all cruises over the deeper parts of the Nordic Seas are from the period 1991 to 2003.

Most of the oxygen concentrations have been determined from discrete samples of water drawn from water sampling bottles (e.g. Niskin bottle), using the Winkler titration method with visual or spectrophotometric endpoint detection (Table 1). For the 58AA19980308(122), 58AA20010527(125), and 58GS20030922(128) cruises only some samples at each station were analysed using the Winkler titration method and these were used to calibrate oxygen measurements from the CTD oxygen sonde. The calibrated CTD oxygen measurements were then reported as oxygen for these three cruises.

\section{Quality control}

The quality control procedures consisted of a primary quality control and a consistency analysis (secondary quality control). Details on these are provided in the following two sections.

\subsection{Primary quality control}

The oxygen data from the Nordic Seas were first subjected to a primary $\mathrm{QC}$, i.e. the detection and flagging of outliers and other irregular data points (Tanhua et al., 2010a). All stations were visually studied and clear outliers were flagged or corrected whenever this was possible. In particular for the cruises from UoB where the original lab sheets were available some errors could be corrected and eliminated. 
Especially for one cruise (58AA19970225 (121)) the oxygen data in the file submitted to CARINA were clearly far too high. When checking the lab sheets it was found that these data were quite different from what had actually been submitted to CARINA, and the file was changed to contain the oxygen values from the lab sheets.

\subsection{Secondary quality control (consistency analyses)}

Only cruises with stations that had oxygen data below 1900 dbar were subjected to secondary QC (see Fig. 2). Hence, the data from 32L919920715 (78), 32L919930718 (79), and Iceland Sea time series (184) were not included in this analysis, and these three have been labelled NC (not considered) under recommendations in Table 1.

The consistency of the Nordic Seas oxygen data was evaluated using a crossover and an inversion analysis (Gouretski and Jancke, 2001; Johnson et al., 2001; Tanhua et al., 2010a). A crossover analysis is an objective comparison of deep water data from one cruise with data from other cruises in the same area. First the crossover points were found by identifying all station pairs from different cruises, within $300 \mathrm{~km}$ from each other. Each cruise pair's crossover stations were then further partitioned into at most 6 clusters; groups of data within a circle with a radius of at most $175 \mathrm{~km}$, using a k-means clustering routine (Seber, 1984), each containing at least two stations from each cruise. The data from each station in the cluster were then interpolated into $50-\mathrm{m}$ intervals, and, using the values from deeper than $1900 \mathrm{dbar}$, the weighted mean offset and standard deviation for each cruise pair was determined. In contrast to other regions, in the Nordic Seas depth was used as the ordinate rather than temperature or density, due to the small gradients of the two latter parameters in this region. Also note that whereas the analysis in the other CARINA regions was carried out using data from deeper than $1500 \mathrm{dbar}, 1900 \mathrm{dbar}$ was used as the cut off depth in the Nordic Seas because deep convection to depths below $1500 \mathrm{dbar}$ is now and then observed (Ronski and Budéus, 2005). The result of the crossover analysis is an offset and it was quantified as a multiplicative factor for oxygen, since problems in standardization are the most likely source of error for this variable. The offsets and their standard deviations were then used as input for the inversion analysis.

The inversion analysis uses least square models to determine the corrections that maximize the consistency between cruises and it also determines the uncertainty of these corrections. Johnson et al. (2001) presented three models of different complexity, and two were used in the present work: (1) the Weighted Least Squares (WLSQ) which weight each offset by its standard deviation so that offsets with large uncertainty are less influential than offsets with smaller uncertainty, and (2) the Weighted Dampened Least Squares (WDLQ) which additionally takes into account a priori assumptions on the expected quality of the data from the dif-

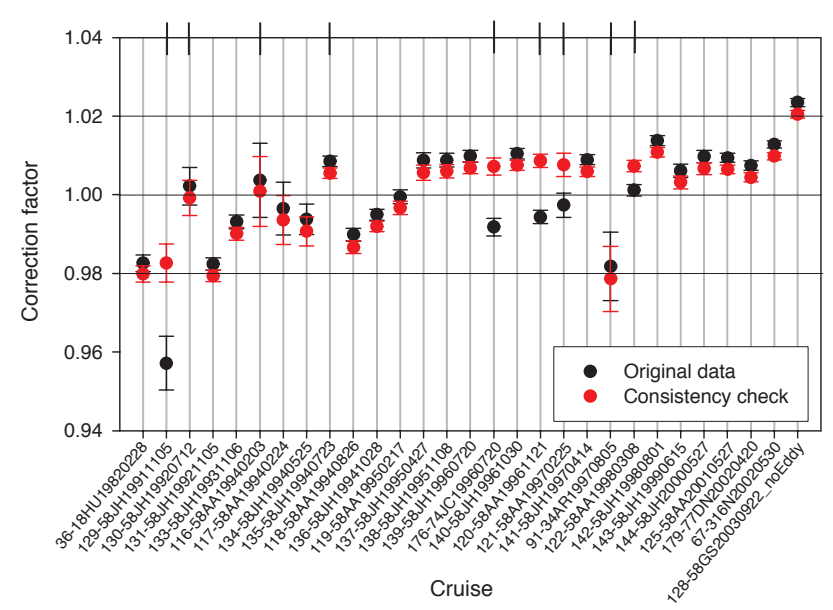

Figure 3. Oxygen corrections (multiplicative) and their uncertainties (vertical bars) determined through the WLSQ inversion of the crossover offsets from data with and without corrections applied. 58GS20030922 (128) had several stations in a submesoscale coherent eddy (Kasajima et al., 2006), the "_noEddy" signifies that these data were removed prior to this analysis. Note that the cruises have been sorted by time in this figure. The crossover results that were used in the inversions to prepare this figure can be accessed at the CARINA website (http://cdiac.ornl.gov/oceans/ CARINA/Carina_inv.html). The vertical lines through the upper $\mathrm{x}$ axis indicates the cruises that were singled out for adjustment considerations.

ferent cruises, expressed as dampening factors. The reader is referred to Johnson et al. (2001) for further details on the approaches. The corrections that were determined for the oxygen data using the WLSQ inversion of the crossover offsets are shown with their uncertainties in Fig. 3 (black dots). (The crossover results in themselves can be accessed at the CARINA website http://cdiac.ornl.gov/oceans/CARINA/ Carina_inv.html).

Before these results are interpreted we have to make clear that there has been a trend of decreasing oxygen values in the deep Greenland Sea caused by an increasing fraction of Arctic deep waters in this area (Blindheim and Rey, 2004, for the period 1981-2000; Botnen, 2009, for the period 19932008). This is evident in the inversion results as well; in Fig. 3 there is a tendency for increasing correction factors with time, reflecting the decreasing oxygen values.

After this first inversion of the crossover offsets, some cruises were selected for further consideration. This was not done on basis of offset from the " 1 " line in Fig. 3, but rather on the basis of correction factors that were clearly different from the correction factors of the other cruises in the same time interval considering the trend mentioned above. The 58JH19911105 (129) values seem very high (have a correction factor below 0.96) while the data from $58 \mathrm{JH} 19920712$ (130), 58AA19940203 (116), and 58JH19940723 (135) seem a bit low compared to the other cruises from this time 
(have higher correction factor). The data collected after 1995 clearly falls into a high and a low group: the oxygen data from 74JC19960720 (176), 58AA19961121 (120), 58AA19970225 (121), and 58AA19980308 (122) appear to be somewhat higher than the data from the other cruises from this period (i.e. the correction factor is lower for these four cruises) and the 34AR19970805 (91) oxygen data seem much higher than the data from any of the other cruises from this period.

\subsection{Recommendations}

Given the outcome of the crossover and inversion analyses the following cruises were considered further: $58 \mathrm{JH} 19911105$ (129), 58JH19920712 (130), 58JH19940723 (135), 34AR19970805 (91), 58AA19940203 (116), 74JC19960720 (176), 58AA19961121 (120), 58AA19970225 (121), and 58AA19980308 (122). These cruises are marked with a vertical bar at the top of Fig. 3 .

\subsubsection{JH19911105 (129)}

The inversion result suggested that these data were too high. However, this cruise had entered CARINA at a very late stage of our analyses and had not been subject to careful primary QC before the crossover analysis, and the offset was due to data from a single station at $3.2^{\circ} \mathrm{E}$ and $74.5^{\circ} \mathrm{N}$, which had very high oxygen values of around $319-320 \mu \mathrm{mol} \mathrm{kg}{ }^{-1}$. This is $10-20 \mu \mathrm{mol} \mathrm{kg}{ }^{-1}$ higher than what is normally measured in these waters. After our analyses the data originator (F. Rey) was contacted. He recommended that the data from that station should be flagged 3; this recommendation has been implemented in the data product. Eventually no adjustment was applied.

\subsubsection{JH19920712 (130)/58JH19940723 (135)/ 34AR19970805 (91)}

All of these cruises took place over the Greenland-Scotland ridge. This is outside the Greenland Sea where most of the other cruises took place (Fig. 2) and the number of crossovers was limited. Given this, and given that this is a highly variable region, we feel that we do not have enough evidence to recommend a specific adjustment for these cruises. To signify this, they have been labelled not considered (NC) in Table 1.

\subsubsection{AA19940203 (116)}

These data appear low. The cruise took place in the northern Greenland Sea (Fig. 2), and it is not inconceivable that influence of deep Arctic waters is stronger here (confirmed by salinity analyses, salinity is a bit high (Olsen et al., 2009; their Fig. 4)), leading to lower oxygen values. Thus we do not recommend that these data are adjusted.
Table 2. Results of the crossover and inversion (WDLSQ) analysis of the cruises falling in a high and a low group, described in Sect. 3.3.4.

\begin{tabular}{lccc}
\hline EXPOCODE & dampening factor & adjustment & covariance \\
\hline 58JH19960720 & 1 & 1 & 0 \\
74JC19960720 & 1.1 & 0.98 & 0.027 \\
58JH19961030 & 1 & 1 & 0 \\
58AA19961121 & 1.1 & 0.98 & 0.016 \\
58AA19970225 & 1.1 & 0.99 & 0.039 \\
58JH19970414 & 1 & 1 & 0 \\
58AA19980308 & 1.1 & 0.99 & 0.017 \\
58JH19980801 & 1 & 1 & 0 \\
58JH19990615 & 1 & 1 & 0 \\
\hline
\end{tabular}

\subsubsection{JC19960720 (176)/58AA19961121 (120)/ 58AA19970225 (121)/58AA19980308 (122)}

These cruises all belong to the "high" group of the post 1995 data. By high we mean that inversion suggest that the data should be adjusted down to be consistent with the observed trend. To determine the best correction factors for this group of cruises a crossover and inversion analysis including only cruises covering the period 1996 to 1999 was carried out. The crossover offsets were this time inverted using the Weighted Dampened Least Squares (WDLSQ) approach. Specifically, the dampening factor (i.e. allowed correction) of the "good" cruises was set to 1 , i.e. we assume a priori that these data are correct. The dampening factor for the high cruises was set to 1.1 (i.e. a correction of up to $10 \%$ is allowed). Table 2 provides an overview of the cruises included, the dampening factors, and the recommended adjustments. Corrections on the order of 0.98 and 0.99 are suggested by the inversion. We recommend that these are applied on the data. The magnitudes of these corrections (1$2 \%)$ are slightly larger than what is regarded as uncertainty of the Winkler method $(<1 \%)$.

\section{Consistency test of final Nordic Seas oxygen data}

After the recommendations of the secondary QC were implemented, all the oxygen data were plotted for each cruise against depth (red dots) on a background (grey dots) of all the Nordic Seas oxygen data in Fig. 2. Only the four above mentioned cruises (Sect. 3.3.4) have corrected values in this figure, the other cruises have not been adjusted. In order to evaluate the consistency of these final Nordic Seas oxygen data, a new crossover analysis was carried out. The corrections determined through the WLSQ inversion of the crossover offsets are shown in Fig. 3 (red dots). With the exception of the three ridge cruises, 58JH19920712 (130), 58JH19940723 (135) and 34AR19970805 (91), the inversion 
suggests a trend of decreasing oxygen, which is consistent with the observations in the deep Greenland Sea presented by Blindheim and Rey (2004) and Botnen (2009). Given this trend, these data appear consistent to approximately $\pm 1 \%$, which corresponds to $\pm 3 \mu \mathrm{mol} \mathrm{kg}{ }^{-1}$ in the deep Nordic Seas.

Four of the five Nordic Seas cruises in common with the Atlantic Ocean subset of CARINA (Stendardo et al., 2009) had oxygen data (58JH19920712 (130), 58JH19940723 (135), 34AR19970805 (91) and 58AA20010527 (125)). The aim was, in order to ensure consistency between the regions, that these cruises should be evaluated independently in each region. Unfortunately there were not enough deep stations in both basins for independent assessments in each. The recommendations for these cruises are, however, the same in the final CARINA data product for both regions.

\section{Data access}

The whole CARINA database is published at the CARINA home page at http://cdiac.ornl.gov/oceans/CARINA/Carina_ inv.html. It contains 188 individual cruise files in commaseparated WHP exchange format. Condensed metadata are contained in the header of each data file, the data in these files have not been adjusted according to the recommendations presented here. They have, however, been adjusted in the three merged, comma-separated data files with the data products, one for each of the CARINA regions, the Arctic Mediterranean Seas, the Atlantic Ocean, and the Southern Ocean.

The CARINA home page also contains all the results of the consistency analyses that were used to determine the corrections, including figures with the crossover results, and an overview table that lists the corrections that have been applied to the data products, this table can be exported to a csv-format file.

Acknowledgements. This effort would not have been possible without support from the Geophysical Institute, University of Bergen (for E.F.) and the Norwegian Research Council through A-CARB (188167, for A.O.). Additional support from the EU through IP CARBOOCEAN (511176), the International Ocean Carbon Coordination Project (IOCCP), and the Hanse Institute for Advanced Study (HWK, Delmenhorst, Germany) have been very valuable. We would also like to express our gratitude to R. M. Key at Princeton University, T. Tanhua at Leibniz-Institut für Meereswissenschaften and S. van Heuven at University of Groningen whose extensive efforts made the CARINA project possible. Finally, we would like to thank the investigators who collected the data at sea, often during adverse conditions, and contributed their data to the CARINA project. This is contribution no. A284 of the Bjerknes Centre for Climate Research.

Edited by: M. Hoppema

\section{References}

Blindheim, J. and Rey, F.: Water-mass formation and distribution in the Nordic Seas during the 1990s, ICES J. Mar. Sci., 61, 846863, 2004.

Botnen, H. A.:T he development of oxygen content in the Greenland Sea from 1993 to 2008, MSc thesis, University of Bergen, Norway, 71 pp., 2009.

Gouretski, V. V. and Jancke, K.: Systematic errors as the cause for an apparent deep water property variability: global analysis of the WOCE and historical hydrographic data, Prog. Oceanogr., 48, 337-402, 2001.

Jeansson, E., Olsson, K. A., Tanhua, T., and Bullister, J. L.: Nordic Seas and Arctic Ocean CFC data in CARINA, Earth Syst. Sci. Data, 2, 79-97, 2010, http://www.earth-syst-sci-data.net/2/79/2010/.

Johnson, G. C., Robbins, P. E., and Hufford, G. E.: Systematic adjustments of hydrographic sections for internal consistency, J. Atmos. Ocean. Tech., 18, 1234-1244, 2001.

Jutterström, S., Anderson, L. G., Bates, N. R., Bellerby, R., Johannessen, T., Jones, E. P., Key, R. M., Lin, X., Olsen, A., and Omar, A. M.: Arctic Ocean data in CARINA, Earth Syst. Sci. Data, 2, 71-78, 2010, http://www.earth-syst-sci-data.net/2/71/2010/.

Kasajima, Y., Olsson, K. A., Johannessen, T., Messias, M.-J., Jeansson, E., Bellerby, R. G. J., and Skjelvan, I.: A submesoscale coherent eddy in the Greenland Sea in 2003, J. Geophys. Res., 111, C07013, doi:10.1029/2005JC003130, 2006.

Key, R. M., Tanhua, T., Olsen, A., Hoppema, M., Jutterström, S., Schirnick, C., van Heuven, S., Kozyr, A., Lin, X., Velo, A., Wallace, D. W. R., and Mintrop, L.: The CARINA data synthesis project: introduction and overview, Earth Syst. Sci. Data, 2, 105121, 2010, http://www.earth-syst-sci-data.net/2/105/2010/.

Olafsson, J. and Olsen, A.: Nordic Seas nutrients data in CARINA, Earth Syst. Sci. Data Discuss., 3, 55-78, 2010, http://www.earth-syst-sci-data-discuss.net/3/55/2010/.

Olsen, A.: Nordic Seas total dissolved inorganic carbon data in CARINA, Earth Syst. Sci. Data, 1, 35-43, 2009a, http://www.earth-syst-sci-data.net/1/35/2009/.

Olsen, A.: Nordic Seas total alkalinity data in CARINA, Earth Syst. Sci. Data, 1, 77-86, 2009b, http://www.earth-syst-sci-data.net/1/77/2009/.

Olsen, A., Key, R. M., Jeansson, E., Falck, E., Olafsson, J., van Heuven, S., Skjelvan, I., Omar, A. M., Olsson, K. A., Anderson, L. G., Jutterström, S., Rey, F., Johannessen, T., Bellerby, R. G. J., Blindheim, J., Bullister, J. L., Pfeil, B., Lin, X., Kozyr, A., Schirnick, C., Tanhua, T., and Wallace, D. W. R.: Overview of the Nordic Seas CARINA data and salinity measurements, Earth Syst. Sci. Data, 1, 25-34, 2009, http://www.earth-syst-sci-data.net/1/25/2009/.

Ronski, S. and Budéus, G.: Time series of winter convection in the Greenland Sea, J. Geophys. Res., 110, C04015, doi:10.1029/2004JC002318, 2005.

Seber, C. A. F.: Multivariate Observations, NJ, John Wiley \& Sons, Inc, 1984.

Stendardo, I., Gruber, N., and Krtzinger, A.: CARINA oxygen data in the Atlantic Ocean, Earth Syst. Sci. Data, 1, 87-100, 2009, http://www.earth-syst-sci-data.net/1/87/2009/. 
Tanhua, T., van Heuven, S., Key, R. M., Velo, A., Olsen, A., and Schirnick, C.: Quality control procedures and methods of the CARINA database, Earth Syst. Sci. Data, 2, 35-49, 2010a, http://www.earth-syst-sci-data.net/2/35/2010/.

Tanhua, T., Steinfeldt, R., Key, R. M., Brown, P., Gruber, N., Wanninkhof, R., Perez, F., Körtzinger, A., Velo, A., Schuster, U., van Heuven, S., Bullister, J. L., Stendardo, I., Hoppema, M., Olsen, A., Kozyr, A., Pierrot, D., Schirnick, C., and Wallace, D. W. R.: Atlantic Ocean CARINA data: overview and salinity adjustments, Earth Syst. Sci. Data, 2, 17-34, 2010b,

http://www.earth-syst-sci-data.net/2/17/2010/. 